\title{
Improving prescribing, junior doctor efficiency and confidence in the acute management of patients following primary percutaneous coronary intervention using a bespoke clerking pro forma
}

\author{
Authors: Jonathan Easaw, Ravi Shaunak, Daniel Hammersley and Vinod Achan
}

\begin{tabular}{|c|c|c|c|c|c|c|c|c|c|}
\hline Medication & Aspirin & $\begin{array}{l}\text { Anti- } \\
\text { platelet }\end{array}$ & $\begin{array}{l}\text { ACEi/ } \\
\text { ARB }\end{array}$ & $\begin{array}{l}\text { Beta } \\
\text { blocker }\end{array}$ & Statin & $\begin{array}{l}\text { GTN } \\
\text { spray }\end{array}$ & Analgesia & $\begin{array}{l}\text { Magnesium } \\
\text { sulphate }\end{array}$ & Sando-K ${ }^{\circledR}$ \\
\hline $\begin{array}{l}\text { Percentage prescribed } \\
\text { pre-pro forma, }(\%)\end{array}$ & 100 & 100 & 81 & 81 & 89 & 44 & 30 & 67 & 59 \\
\hline $\begin{array}{l}\text { Percentage prescribed with pro } \\
\text { forma, }(\%)\end{array}$ & 100 & 100 & 92 & 75 & 92 & 100 & 67 & 100 & 100 \\
\hline Difference in percentage, (\%) & 0 & 0 & +11 & -6 & +3 & +56 & +37 & +33 & +41 \\
\hline
\end{tabular}

\section{Aims}

To design and implement a bespoke clerking pro forma for patients following primary percutaneous coronary intervention (pPCI) to improve guideline-based prescribing, junior doctor efficiency and confidence.

\section{Methods}

Patients who underwent PPCI in a district general hospital over 1 month were identified via the hospital coding system. Their notes and drug charts were retrospectively assessed to identify whether the National Institute for Health and Care Excellence recommended regular medications (including dual antiplatelet medication, beta blockers, angiotensin converting enzyme inhibitors (ACEi) / angiotensin receptor blockers (ARB) and statins) had been prescribed on clerking. Prescriptions of 'as required' (prn) medications (including glyceryl trinitrate, analgesia and electrolyte replacement) were also assessed. The bespoke clerking pro forma was designed and used to admit all pPCI patients; this contained a prompt to prescribe the guideline-recommended regular and prn medications. After introduction of the PPCI clerking pro forma, the prescription of these medications was re-audited over a 1-month period. A confidence questionnaire for clinicians was used to assess the impact of the pro forma; specifically, rating confidence levels out of 10 for admitting pPCI patients before and after introduction of the pro forma. It also assessed the length of clerking before and after the introduction of the pro forma.

Results

A total of 27 patients were identified in the pre-pro forma group and 12 patients in the post-pro forma group. Following introduction of the pro forma, prescribing of ACEi/ARB, statins and prn medications improved. The impact of the pro forma on prescribing is demonstrated in Table 1.

Where these medications were not prescribed, omissions were justified on the pro forma (eg bradycardia, intolerance). This corroborated with our performance in the Myocardial Infarction National Audit Project in 2016, which revealed that $99.5 \%$ of patients received guideline-based medications on discharge. Eighteen confidence questionnaires were filled in by junior doctors showing a rise in average confidence scores from $5 / 10$ to $9 / 10$. Additionally, the average clerking time reduced from over 25 minutes to 5-15 minutes.

\section{Conclusion}

The PPCI clerking pro forma has proven to be a useful and cost-effective aid to junior clinicians in pPCI admissions, as demonstrated by improved medication prescribing, clinician confidence and time efficiency.

\section{Conflict of interest statement}

None declared 